\title{
Labyrinthe
}

$8 \mid 2001$

Numéro 8

\section{Six ou Huit Poèmes de Kojo Laing}

Traduction inédite de l'anglais par Guillaume Cingal. Pour des raisons techniques indépendantes de notre volonté, la mise en ligne de ce texte est malheureusement retardée. Elle sera effectuée dès que possible.

\section{Kojo Laing}

\section{OpenEdition}

\section{Journals}

Electronic version

URL: http://journals.openedition.org/labyrinthe/885

DOI: 10.4000/labyrinthe.885

ISSN: 1950-6031

\section{Publisher}

Hermann

Printed version

Date of publication: 1 January 2001

Number of pages: 91-106

\section{Electronic reference}

Kojo Laing, «Six ou Huit Poèmes de Kojo Laing », Labyrinthe [Online], 8 | 2001, Online since 19 June 2005, connection on 01 May 2019. URL : http://journals.openedition.org/labyrinthe/885 ; DOI: $10.4000 /$ labyrinthe.885

This text was automatically generated on 1 May 2019.

Propriété intellectuelle 


\section{Six ou Huit Poèmes de Kojo Laing}

Traduction inédite de l'anglais par Guillaume Cingal. Pour des raisons techniques indépendantes de notre volonté, la mise en ligne de ce texte est malheureusement retardée. Elle sera effectuée dès que possible.

Kojo Laing 